\title{
A REVIEW OF: EDUCATION FOR A DEMOCRATIC SOCIETY - CURRICULUM IDEAS FOR TEACHERS
}

\author{
Floyd $O^{\prime} B$ rien \\ Stockton, California
}

Campbell, Duane E. Education for a Democratic Society - Curriculum Ideas for Teachers. Cambridge, Mass: Schenkman, 1980.

Duane Campbell presents a strategy for teaching social action skills to students in elementary and secondary schools. His 15 years of experience in the educational enterprise directed him to the classroom teacher as the pivot point in this endeavor. Would classroom teachers read his book, Education for a Democrotic Society, they would teach their students effective sociai action skills, and in the process, become effective social activisis themselves. Campbell wrote the book for this purpose, but only future tests will demonstrate whether the book accomplishes its objective. Regardless, my review will focus on attributes of the book that are likely to effect the objective.

Campbell considers traditional teacher behavior to reflect and perpetuate a corrupt social structure, but he laments the condition of most radical analyses of education, which provide little guidance for change. He promises to translate his analysis into directions for concrete action. These directions include content and strategies of instruction. Regarding content, Campbell attends to teacher needs by describing the lack of motivation students have in studying traditional societal myths, and proposes a significant increase in motivation when working class students study the realities of our culture. He further prompts teachers to use his strategy through lessening their work by providing them with completed lesson plans. The instructional strategy he proposes is one of democratic, problem-solving, and discovery-oriented methods. He provides case studies throughout his discussion that describe successes. Examples include classroom study of pollution resulting in the establishment of recycling centers, study of transportation concluding with the County's laying bicycle paths, study of elections prompting a registration drive, and publication of a history curriculum developed by teachers for black students with low reading levels that not only taught history, but improved students' reading levels by two grades. These examples should serve to offer social activist teachers the potential of reinforcement for using this strategy, as well as maintain their reading of the book.

More conservative teachers are unlikely to continue reading Campbell's analysis, especially when he admits in the introduction that his analysis will be blunt, direct, offensive to many, strong, and militant. Being aware of this, Campbell tells such teachers to skip the analysis section, read the lesson plans in the final chapter, try them with students, and, if intrigued, then read the analysis section. This move appears similar to those made by behaviorists in getting behavior analysis into classrooms: have teachers try a behavior change prescription first, then, have them learn the basics of the field. Campbell's first lesson plan deals with voter registration, generally inoffensive to all. Unfortunately, the first content objective these conservative teachers will read is likely to be offensive: "Students will know that Chicanos seized control of the schools and the government ..." Hopefuliy, some will continue reading past this point, and find other items in that lesson pian not so offensive.

Campbell blames the authoritarian teaching strategy for the students' lack of motivation to study, their not learning the skills required to participate in democracy (e.g., social responsibility, group work, problem analysis, goal setting), and the apathetic state of graduates. As mentioned earlier, motivation would be enhanced in his model by students' selecting matters of importance to the working class (e.g., busing, rent control, unionism, consumerism). Within group processes, students would study issues, analyze findings, determine goals, evaluate alternative actions, select and implement actions, evaluate, modify, etc. In the process, students would learn that their actions can make a difference. Campbell calls this personal adequacy and self image. Radical behaviorists might call it self efficacy or an increased probability to act due to past reinforcement for doing so. Regardless of what we call it, graduates of Campbell's strategy would not be apathetic; they would be social activists.

Most readers of this journal will find the goals of Campbell's strategy laudable, consider his analysis of the role of education in perpetuating a corrupt social system to be astute, and be convinced that teachers' following his plan would be one solution. Most readers might disagree with his claim that the authoritarian system is due, in part, to the imperialism of science in education. The essence of his argument rests on the fallacy of equating science with positivism, reductionism, and an inability to deal with the mediation of behavior by consciousness. Instead, he recommends adding to "rationality" a "dialectical process of knowing" - a recommendation most readers would likely support. Whether teachers follow his plan, and if they did, whether the education institution would permit it, and if it did, whether society's power structure would continue supporting education are likely to be the issues upon which most readers will rest their evaluation of this work. 